Article

\title{
Preparation and In Vitro Evaluation of Glycyrrhetinic Acid-Modified Curcumin-Loaded Nanostructured Lipid Carriers
}

\author{
Yang Chu ${ }^{1,2}$, Dan $\mathrm{Li}^{3}$, Yi-Fan Luo ${ }^{1,2}$, Xiao-Jin $\mathrm{He}^{4}$ and Ming-Yan Jiang ${ }^{1, *}$ \\ 1 Department of Pharmacy, The First Affiliated Hospital of China Medical University, 155 Nanjing \\ Street, Shenyang 110001, China \\ 2 Department of The First Clinical Pharmacy, China Medical University, 92 Bei'er Road, Shenyang \\ 110001, China \\ 3 Department of Pharmacy, Central Hospital Attached to Shenyang Medical College, No. 5 the 7 th \\ south-west Road, TieXi district, Shenyang 110024, China \\ 4 School of Pharmacy, Shenyang Pharmaceutical University, 103 Wenhua Street, Shenyang 110016 , \\ China
}

* Author to whom correspondence should be addressed; E-Mail: ydyyyxb@163.com; Tel.: +86-024-8328-2619.

Received: 14 November 2013; in revised form: 11 February 2014 / Accepted: 17 February 2014 / Published: 21 February 2014

\begin{abstract}
Curcumin, a phenolic antioxidant compound derived from the rhizome of the turmeric plant Curcuma longa, has proven to be a modulator of intracellular signaling pathways that control cancer cell growth, inflammation, invasion and apoptosis, revealing its anticancer potential. In this study, a Glycyrrhetinic Acid-Modified Curcumin-Loaded Nanostructured Lipid Carrier (Cur-GA-PEG-NLC) was prepared by the film ultrasound method to improve the tumor-targeting ability. The drug content was detected by an UV spectrophotometry method. The encapsulation efficiency of curcumin in the nanostructured lipid carriers (NLCs) was determined using a mini-column centrifugation method. The encapsulation efficiency for various Cur-GA-PEG-NLC was within the range of $90.06 \%-95.31 \%$ and particle size was between $123.1 \mathrm{~nm}$ and $132.7 \mathrm{~nm}$. An in vitro MTT assay showed that Cur-GA10\%-PEG-NLC had significantly high cellular uptake and cytotoxicity against HepG2 cells compared with other groups.
\end{abstract}

Keywords: curcumin; glycyrrhetinic acid; nanostructured lipid carriers; anti-HepG 2 


\section{Introduction}

Cancer is leading cause of death in the World. Current chemotherapeutic agents such as alkylating agents, mustards, anti-metabolites, spindle poisons, and DNA binders and cutters, target a specific biological pathway, which ultimately shrinks tumor size, but often fails to eradicate tumors or prevent their recurrence. It was reported that repeated treatment with these agents results in tumors resistant to chemotherapy, so it is crucial to identify natural products that might have growth inhibitory and apoptosis induction properties in human cancer cells and without toxicity issues towards normal cells [1]. On the basis of its high pharmacological effect and low toxicity, curcumin might be a potential drug candidate for the treatment of cancer.

Curcumin (Figure 1) is a phenolic antioxidant compound derived from the rhizome of the turmeric plant Curcuma longa. Curcumin is widely used as colorant and dye in the food field [2]. Curcumin is also a prominent anti-inflammation, anti-toxin, anti-cystic fibrosis, anti-Alzheimer's, hepatoprotective and anti-malarial agent, in addition to its anti-cancer properties [3-9]. Many studies have shown that curcumin is a potent inhibitor of arachidonic acid metabolism and cyclooxygenase activity in epidermis and intestinal mucosa [10-14]. Recent studies had found that curcumin inhibited proliferation of Sk-hep-1 cells with a dose-effect relationship. Cell cycle analysis results showed that curcumin treatment resulted in dramatic accumulation of Sk-hep-1 cells at the G0/G1 or G2/M phase, which indicated that curcumin was able to inhibit proliferation and induce apoptosis in Sk-hep-1 cells caused by downregulating the expression of MDR1 mRNA [15]. Because of its good anticancer effects the USA National Cancer Institute (NCI) had listed it as a third generation cancer chemo-preventive drug [16].

Figure 1. Structure of curcumin.

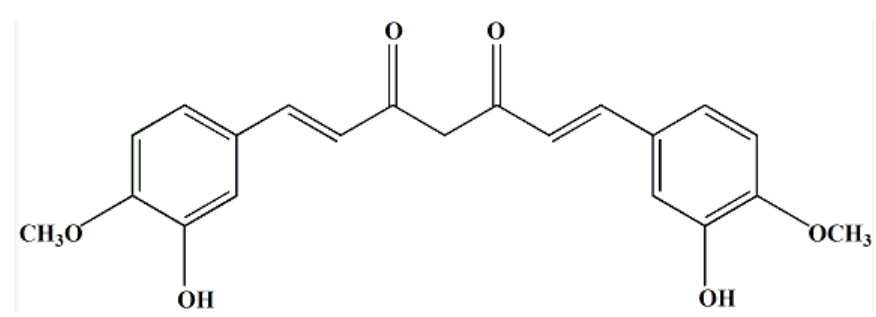

Nanostructured lipid carriers (NLCs) are a new type of drug delivery system generated from solid lipid nanoparticles (SLNs), which offer some benefits in contrast to other colloidal carrier schemes. The solid lipid carrier is a natural or synthetic lipid such as lecithin or triacylglycerol. The liquid oil is dropped into the solid lipid to make nanoparticles with crystalline or amorphous structures. The drug is wrapped in the lipid nucleus and the particle size is between 50-1,000 nm. NLCs show a higher loading capability for compounds and also have a lower water content in their elemental suspensions and a less inclination to unpredictable gelation [17-19]. NLCs provide a controlled pharmaceutical form and an increase in chemical stability of the incorporated drugs. Furthermore, NLCs are a protected carrier which can be produced effortlessly on a large scale [17,20-23].

Glycyrrhetinic acid (GA) is a hydrolysis product of glycyrrhizic acid (GL) which is the main components of the Traditional Chinese Medicine liquorice. The structure of glycyrrhetinic acid is shown in Figure 2. It was reported that there are some highly specific GA binding sites located on the 
surface of liver parenchyma cells. Some researchers also reported that liposomes modified with GA expressed a considerably high affinity to hepatocytes [24-26]. GA conjunction with NLC could produce a smart system with lower toxicity and higher bioactivity. The investigations of GA-mediated targeted drug delivery systems such as liposomes, nanoparticles and polymeric micelles have become more and more popular. In our study, curcumin is formulated as an anticancer agent for liver tumor treatment. We have designed a special NLC combined with an active ligand (GA) to achieve the desired targeting performance.

Figure 2. Structure of glycyrrhetinic acid (GA).

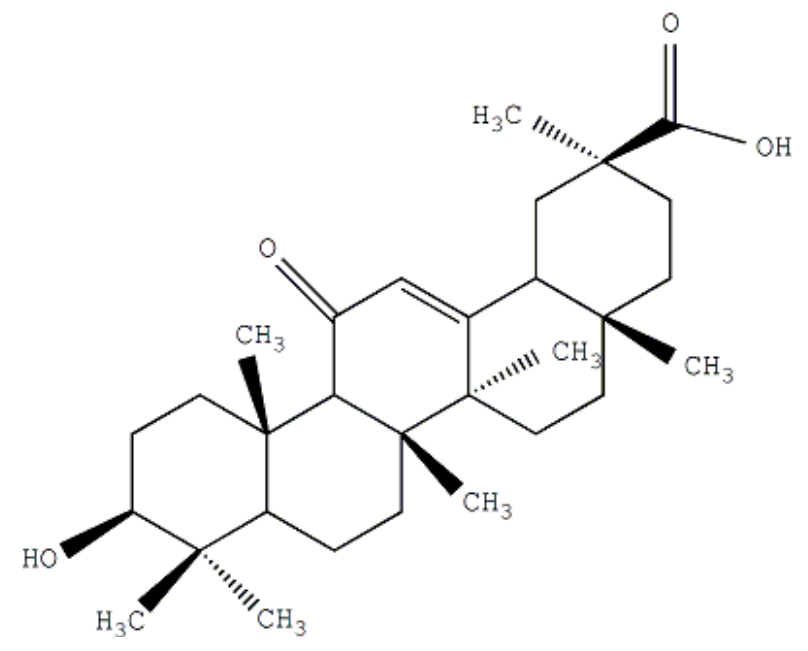

\section{Results and Discussion}

\subsection{Synthesis and the Surface Characterization of GA-Phospholipid Derivative}

The reaction steps are shown in Scheme 1.

Scheme 1. GA-PEG 2000 -DSPE reaction route.

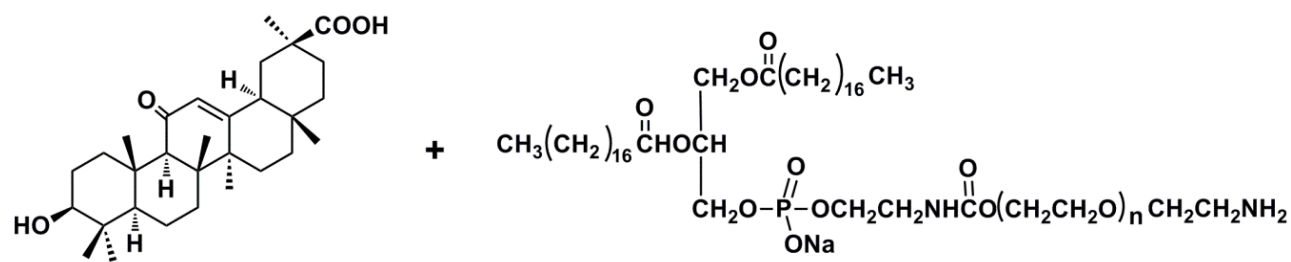

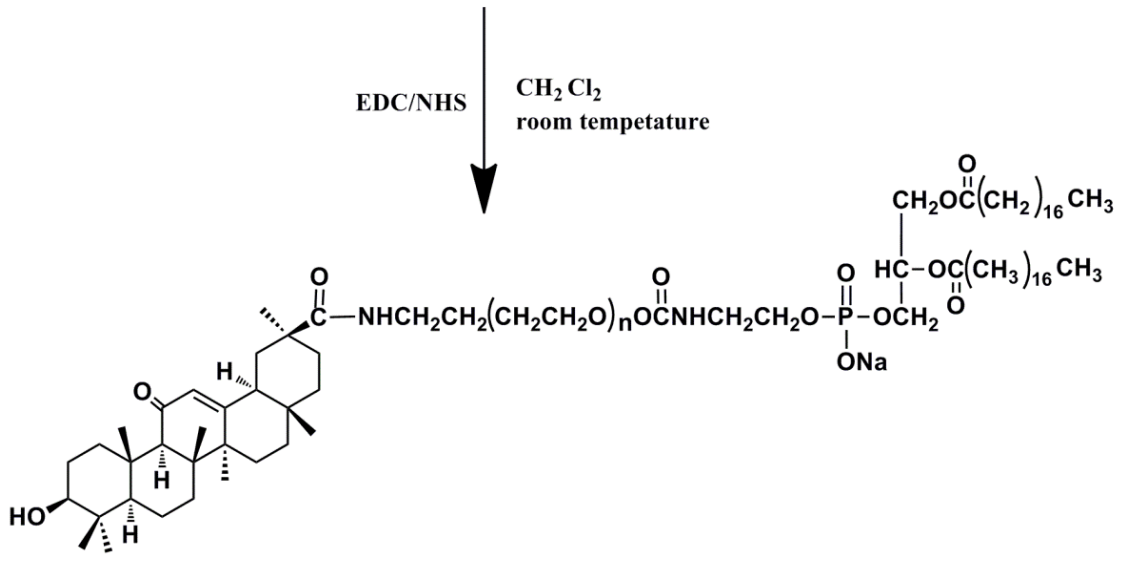




\subsubsection{FT-IR}

Figure 3 shows the FT-IR spectra of GA, DSPE-PEG ${ }_{2000}-\mathrm{NH}_{2}$ and DSPE-PEG $2000-\mathrm{GA}$ polymer. The main resonance peaks of GA were $-\mathrm{OH}\left(3,438 \mathrm{~cm}^{-1}\right),-\mathrm{CH}_{2}\left(2,926 \mathrm{~cm}^{-1}\right),-\mathrm{CH}_{3}\left(1,384 \mathrm{~cm}^{-1}\right)$, $\mathrm{O}-\mathrm{CH}_{2}\left(1,177 \mathrm{~cm}^{-1}\right)$ and $\mathrm{C}=\mathrm{C}\left(1,663 \mathrm{~cm}^{-1}\right)$, while the characteristic peaks of DSPE-PEG $2000-\mathrm{NH}_{2}$ were $\mathrm{N}-\mathrm{C}=\mathrm{O}\left(1,739 \mathrm{~cm}^{-1}\right),-\mathrm{CH}_{2}\left(2,917 \mathrm{~cm}^{-1}\right),-\mathrm{CH}_{3}\left(1,359 \mathrm{~cm}^{-1}\right), \mathrm{O}-\mathrm{CH}_{2}\left(1,113 \mathrm{~cm}^{-1}\right)$ and $\mathrm{C}=\mathrm{C}(1,669$ $\mathrm{cm}^{-1}$ ) respectively. The observed characteristic amide bond peak suggested that the targeted synthetic products were indeed formed. In the FT-IR spectrum of DSPE-PEG $2000-G A$, the appearance of characteristic peaks of $1,741 \mathrm{~cm}^{-1}, 1,645 \mathrm{~cm}^{-1}$ and $1,354 \mathrm{~cm}^{-1}$ confirmed that the $\mathrm{N}-\mathrm{C}=\mathrm{O}$ bond was formed.

Figure 3. FT-IR spectra of GA, DSPE-PEG2000-NH2 and DSPE-PEG2000-GA.

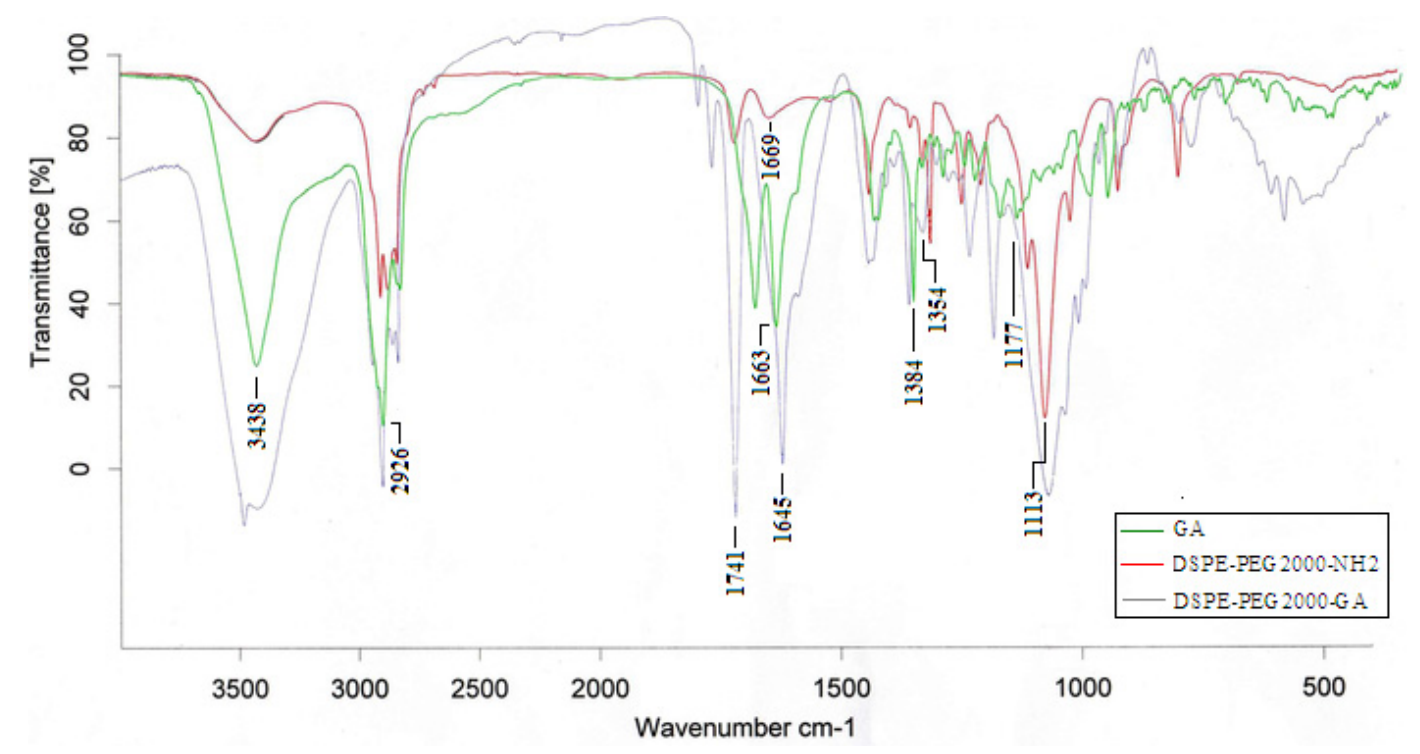

\subsection{2. ${ }^{1} \mathrm{H}-\mathrm{NMR}$}

Figure 4 shows the ${ }^{1} \mathrm{H}-\mathrm{NMR}$ spectra of GA, DSPE-PEG $2000-\mathrm{NH}_{2}$ and DSPE-PEG $2000-\mathrm{GA}$ polymer. The ${ }^{1} \mathrm{H}-\mathrm{NMR}$ spectrum of GA showed the methyl protons at $\delta 0.75-1.5 \mathrm{ppm}$. The ${ }^{1} \mathrm{H}-\mathrm{NMR}$ spectrum of DSPE-PEG ${ }_{2000}-\mathrm{NH}_{2}$ showed the characteristic $-\mathrm{NH}_{2}$ peak at $\delta 1.253 \mathrm{ppm}$, and the characteristic $-\mathrm{CH}_{2}$ - peak at $\delta 3.64 \mathrm{ppm}$. The ${ }^{1} \mathrm{H}-\mathrm{NMR}$ spectrum of DSPE- $\mathrm{PEG}_{2000}-\mathrm{GA}$ contained characteristic peaks of GA $(\delta 0.75-1.5 \mathrm{ppm}),-\mathrm{NH}-(\delta 1.254 \mathrm{ppm})$ and $-\mathrm{CH}_{2^{-}}(\delta 3.64 \mathrm{ppm})$, indicating that the GA was successfully conjugated to DSPE-PEG 2000 .

\subsection{Particle Characterization}

The Cur-NLC, Cur-PEG-NLC and Cur-GA-PEG-NLC formulation containing various concentrations of GA-modified $\mathrm{PEG}_{2000}$-DSPE $(5 \%, 10 \%$ and $15 \%$; w/w) were prepared by the film-ultrasonic technique. As shown in Figure 5, the appearance of Cur-NLC, Cur-PEG-NLC and Cur-GA10\%-PEG-NLC particles was spherical or ellipsoidal with smooth surfaces. Compared with the Cur-NLC, Cur-PEG-NLC and Cur-GA10\%-PEG-NLC have a larger particle size. The particle size, zeta potential, average 
encapsulation efficiency and the drug loading capacity results of Cur-NLC, Cur-PEG-NLC, Cur-GA5\%-PEG-NLC, Cur-GA10\%-PEG-NLC, Cur-GA15\%-PEG-NLC are listed in Table 1.

Figure 4. ${ }^{1} \mathrm{H}-\mathrm{NMR}$ spectra of (a) GA; (b) DSPE-PEG2000-NH2; and (c) DSPE-PEG2000-GA.
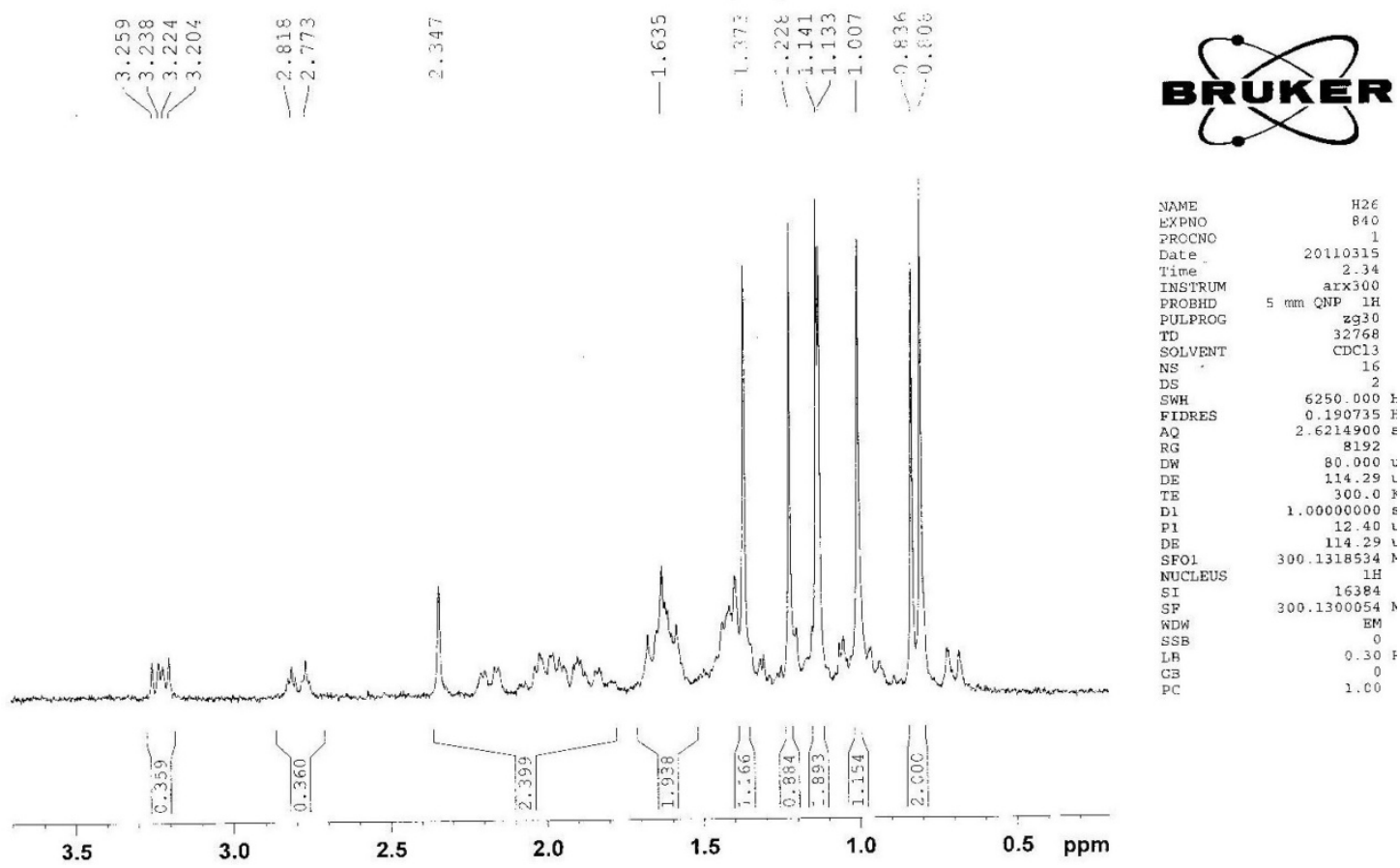

(a)

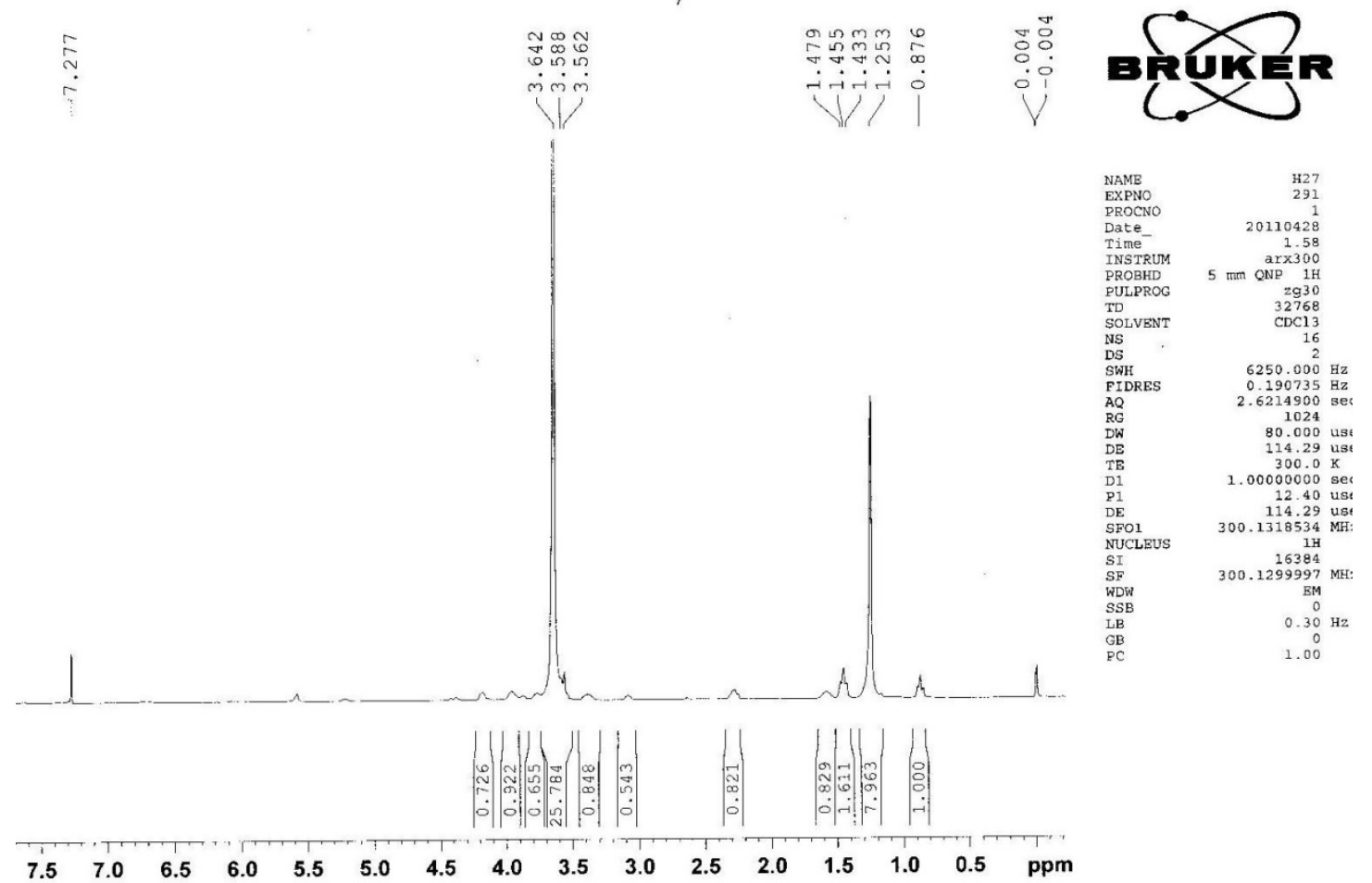

(b) 
Figure 4. Cont.

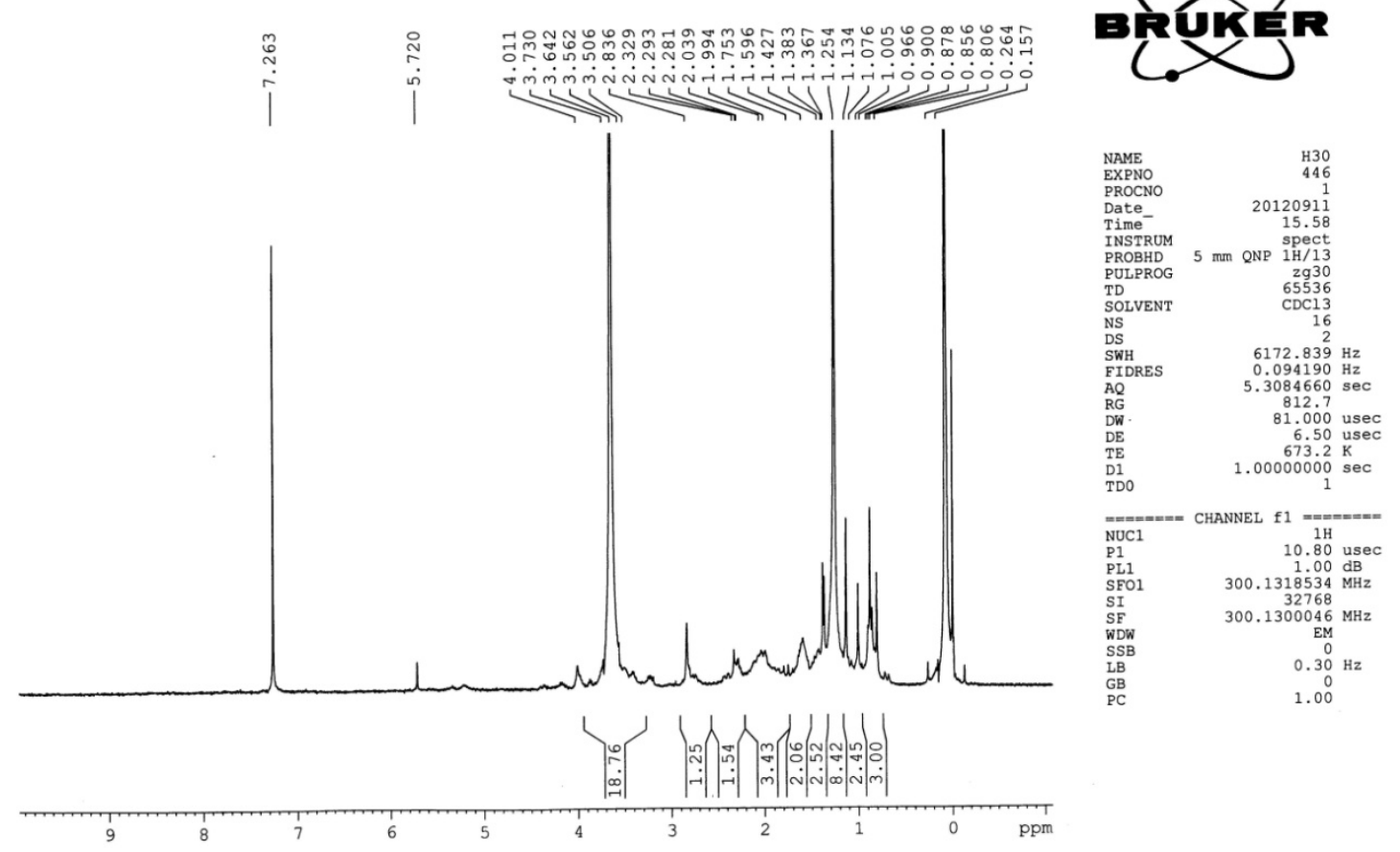

(c)

Figure 5. Transmission electron micrographs (TEM) of (a) Cur-NLC; (b) Cur-PEG-NLC; and (c) Cur-GA10\%-PEG-NLC.

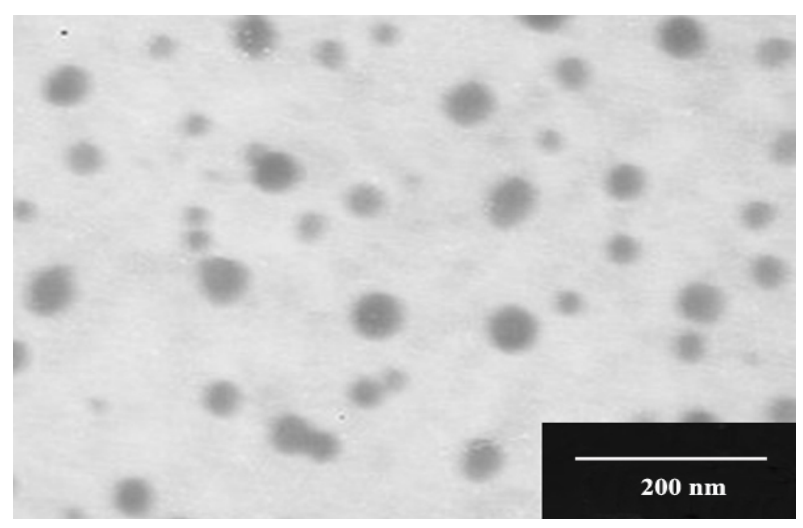

(a)

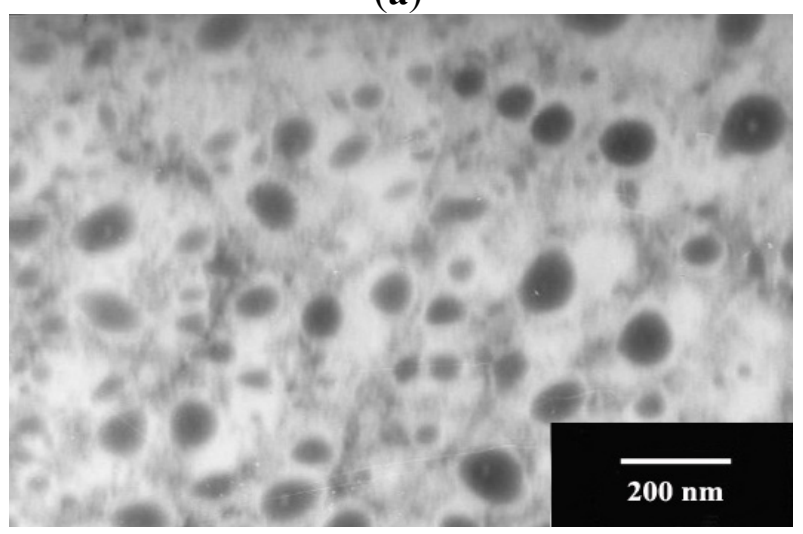

(b) 
Figure 5. Cont.

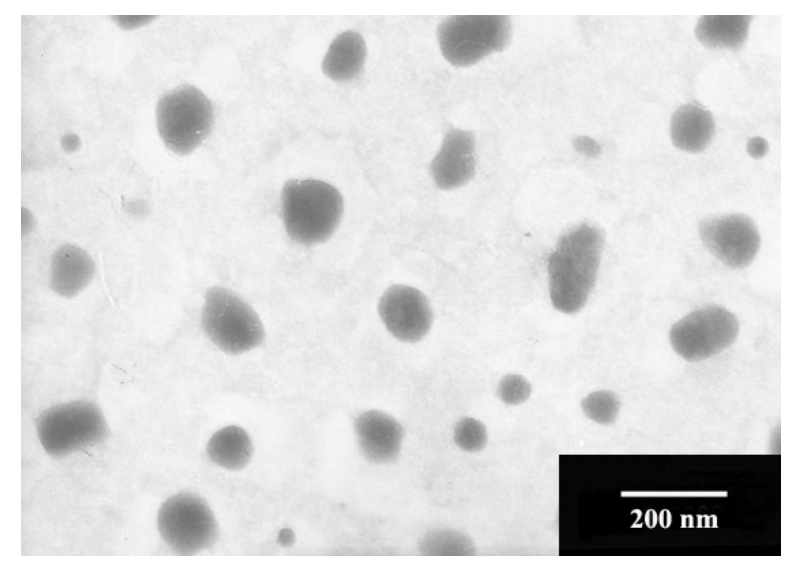

(c)

Table 1. Particle characterization of Cur-NLC, Cur-PEG-NLC and Cur-GA5/10/ $15 \%$-PEG-NLC ( $\bar{x} \pm S D, n=5)$.

\begin{tabular}{ccccc}
\hline \multirow{2}{*}{ Type } & \multicolumn{4}{c}{ Particle Characterization } \\
\cline { 2 - 5 } & $\begin{array}{c}\text { Particle Sizes } \\
(\mathbf{n m})\end{array}$ & $\begin{array}{c}\text { Zeta Potentials } \\
\mathbf{( m V )}\end{array}$ & $\begin{array}{c}\text { Encapsulation } \\
\text { Efficiency (\%) }\end{array}$ & $\begin{array}{c}\text { Drug Loading } \\
\text { Capacity (\%) }\end{array}$ \\
\hline Cur-NLC & $58.3 \pm 8.8$ & $-22.6 \pm 0.88$ & $93.48 \pm 0.86$ & $2.25 \pm 0.32$ \\
Cur-PEG-NLC & $102.4 \pm 13.5$ & $-17.1 \pm 0.53$ & $97.12 \pm 2.45$ & $2.34 \pm 0.28$ \\
Cur-GA5\%-PEG-NLC & $123.1 \pm 15.6$ & $-16.2 \pm 0.48$ & $95.31 \pm 2.18$ & $2.30 \pm 0.30$ \\
Cur-GA10\%-PEG-NLC & $128.4 \pm 15.9$ & $-15.5 \pm 0.37$ & $93.11 \pm 1.76$ & $2.24 \pm 0.22$ \\
Cur-GA15\%-PEG-NLC & $132.7 \pm 16.7$ & $-14.8 \pm 0.32$ & $90.06 \pm 1.12$ & $2.17 \pm 0.24$ \\
\hline
\end{tabular}

\subsection{Cellular Selective Uptake of NLCs}

Figure 6 showed the results of in vitro cellular uptake. Because Cur was trapped in the nanostructured lipid carrier and further internalized into tumor cells by endocytosis, cellular uptake of nanocarriers were higher than in the Cur-solution group. For the same concentration, the cellular uptake of free drug and the preparations were all increased over the incubation time. It was found that the cellular uptake reached a plateau after $6 \mathrm{~h}$ incubation, probably due to the saturation effect.

Figure 6. Cellular uptake content of (a) Cur-PEG-NLC with different GA ratio; and (b) Cur-Solution, NLC, PEG-NLC and GA10\%-PEG-NLC.

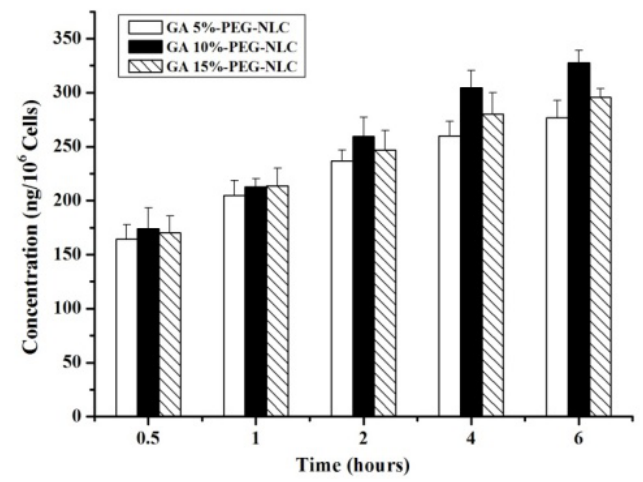

(a)

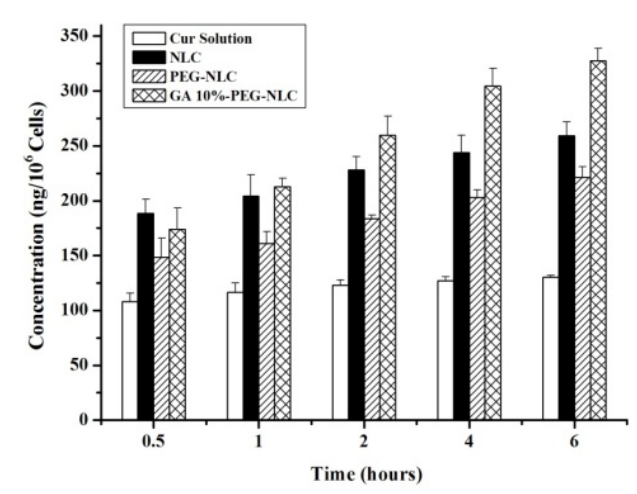

(b) 
A series of the Cur-GA-PEG-NLCs with different GA ratio (5\%, 10\% and 15\%; w/w) was prepared to investigate the influence of GA on the uptake of the preparations. The figure showed that the uptake was time dependent. At $0.5 \mathrm{~h}$ and $1 \mathrm{~h}$, the three types of preparations had similar cell accumulation. However, after $2 \mathrm{~h}$ incubation, Cur-GA10\%-PEG-NLC group had more cellular uptake than the other two groups. This result showed that the $10 \%$ of the GA on the surface of the nanocarrier was achieving the best cellular uptake because of the limited number of receptors on the cell surface. It was also reported that overabundance of ligands may block combination of receptor and ligand due to steric hindrance [27,28].

\subsection{Cytotoxicity to HepG2}

The $\mathrm{IC}_{50}$ values were listed in Table 2 and shown in Figure 7. Cytotoxicity test showed that the $\mathrm{HepG}_{2}$ cell proliferation inhibition rates of free drug and the formulations were concentration and time dependent. The cell growth inhibition rates were mostly increased with the increase in the time incubation and drug concentration. The group of Cur-GA10\%-PEG-NLC had a much higher cytotoxicity than the group of Cur-solution at all the time points and higher than the group of Cur-NLC at 24, $48 \mathrm{~h}$.

Table 2. $\mathrm{IC}_{50}$ values of Cur-solution, Cur-NLC, Cur-PEG-NLC and Cur-GA10\%-PEG$\operatorname{NLC}(\overline{\mathrm{x}} \pm \mathrm{SD}, \mathrm{n}=4)$

\begin{tabular}{ccccc}
\hline \multirow{2}{*}{ T (h) } & \multicolumn{5}{c}{ IC $_{\mathbf{5 0}}(\boldsymbol{\mu}$ g/mL) } \\
\cline { 2 - 5 } & Cur-Solution & Cur-NLC & Cur-PEG-NLC & Cur-GA10\%-PEG-NLC \\
\hline 24 & $42.28 \pm 9.40^{* *}$ & $8.00 \pm 0.97 * *$ & $3.28 \pm 0.16$ & $2.91 \pm 0.70$ \\
48 & $15.60 \pm 1.28 * *$ & $3.87 \pm 0.18^{* *}$ & $3.14 \pm 1.27$ & $2.22 \pm 0.03$ \\
72 & $6.93 \pm 0.61 * *$ & $1.70 \pm 0.31$ & $1.54 \pm 0.04$ & $1.34 \pm 0.24$ \\
\hline \multicolumn{5}{c}{$* * p<0.01$ vs. the group of Cur-GA10\%-PEG-NLC. }
\end{tabular}

Figure 7. The $\mathrm{IC}_{50}$ values of of Cur-solution, Cur-NLC, Cur-PEG-NLC and Cur-GA10\%PEG-NLC ( $\bar{x} \pm S D, n=4)$.

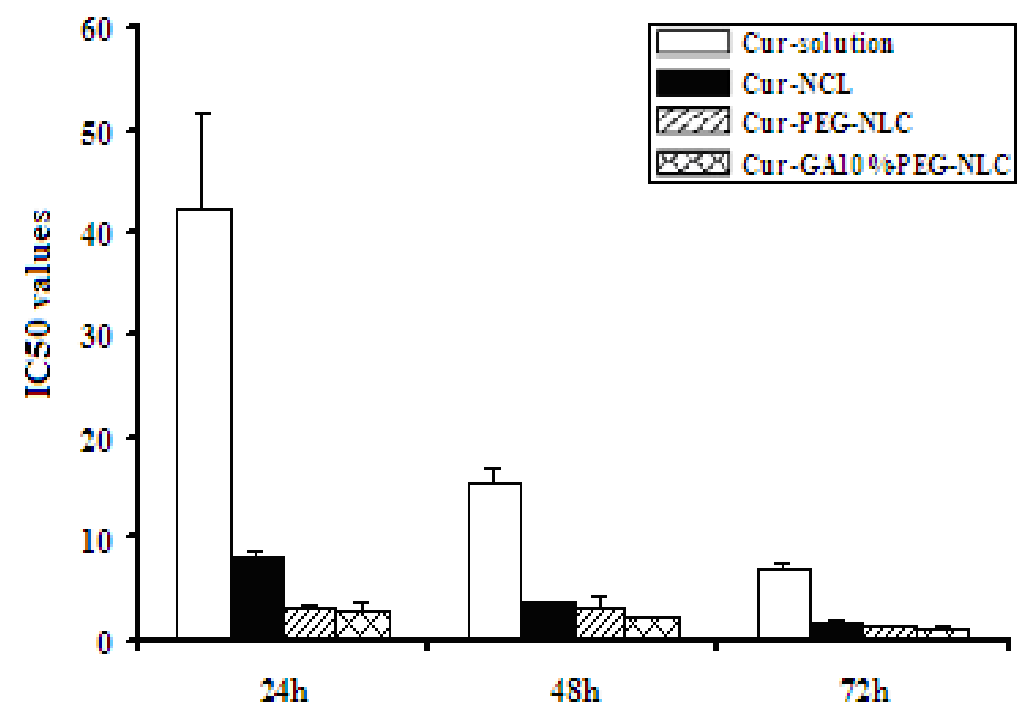




\section{Experimental}

\subsection{General}

Curcumin was purchased from J\&K Scientific Co. (Beijing, China). A curcumin reference was supplied by the National Institutes for Food and Drug Control (Beijing, China). Glycerin monostearate was purchased from Bodi Chemical Co., Ltd. (Tianjin, China). Caprylic/capric acid glycerol ester (Miglyol 812N) was obtained from SASOL Co. (Hamburg, Germany). Polyoxyl (40) Stearate was supplied by Yi Weikang Biological Technology Co., Ltd. (Qingdao, China). Soybean lecithin for injection (PC $>95 \%$ ) was obtained from Tywei Pharmaceutical Co., Ltd. (Shanghai, China). Dextrangel was purchased from Sino-American Biotechnology Co., Ltd. (Henan, China). DSPE-PEG $\mathrm{C}_{2000}-\mathrm{NH}_{2}$ was obtained from Avanti Co. (Alabaster, MI, USA). Human liver hepatocellular carcinoma cell line $\left(\mathrm{HepG}_{2}\right)$ was supplied by Queen \& King Biological Chemical Co., Ltd. (Shanghai, China). All the other chemicals and reagents used were of analytical grade.

\subsection{Preparation of Cur-NLC}

Weighed amounts of lipid (290 mg of Glycerol monostearae/125 mg of Miglyol 812N/91 mg of lecithin) and curcumin (10 mg) were placed into a beaker, and heated up to $75^{\circ} \mathrm{C}$ with a water bath. After dissolving the melt by adding anhydrous ethanol $(5 \mathrm{~mL})$, the organic solvent was removed using a rotary evaporator. A certain amount of surfactant (320 mg of Polyoxyethylene 40 Strearate) was dissolved in the sterile water with sonication and heating at $75{ }^{\circ} \mathrm{C}$ by water bath to produce a surfactant-containing aqueous solution. The aqueous phase was added into the oil phase at $75{ }^{\circ} \mathrm{C}$ with magnetic stirring for $5 \mathrm{~min}$ to prepare the primary emulsion. Redispersion while still hot by an ultrasonic cell crusher for $5 \mathrm{~min}$ and filtering through a $0.22 \mu \mathrm{m}$ microporous membrane, the filtrate was replenished to $10 \mathrm{ml}$ and solidified using an ice bath to obtain the curcumin-loaded nanostructured lipid carrier (Cur-NLC) dispersion.

\subsection{Synthesis of GA-Phospholipid Derivative (GA-PEG $\left.G_{2000}-D S P E\right)$}

GA, DCC and NHS at a certain mole ratio (1.25:1:1) were dissolved in anhydrous methylene chloride $(10 \mathrm{~mL})$, and allowed to react for $3 \mathrm{~h}$ at room temperature. A DSPE-PEG ${ }_{2000}-\mathrm{NH}_{2}$ methylene chloride solution $(5 \mathrm{~mL}, 0.2 \mathrm{mmol} / \mathrm{mL})$ was added into the mixture. The whole synthesis step was performed under nitrogen protection and the mixture was allowed to react for $48 \mathrm{~h}$ at room temperature. After filtration of the final solution to remove the by-product, the target product was obtained by precipitating from the filtrate which was mixed with a suitable amount of ice-col ether aiming to isolate the residual GA. The precipitate was dissolved in DMF and dialyzed for $72 \mathrm{~h}$. The solid product was obtained by freeze drying.

\subsection{Preparation of Cur-PEG-NLC and Cur-GA-PEG-NLC}

According to the method of Section 3.2, Cur-PEG-NLC was prepared by adding $15 \%(\mathrm{w} / \mathrm{w})$ of the total lipid amount of DSPE-PEG 2000 to the oil phase. To prepare a series of Cur-GA-PEG-NLC 
formulations containing various concentration of GA-modified $\mathrm{PEG}_{2000}$-DSPE $(5 \%, 10 \%$ and $15 \%$; w/w), different amounts of GA-PEG $2000-D S P E$ were used.

\subsection{FT-IR and ${ }^{1} H-N M R$ Analysis}

FT-IR spectra of GA, DSPE-PEG ${ }_{2000}-\mathrm{NH}_{2}$ and DSPE-PEG ${ }_{2000}-\mathrm{GA}$ were determined on a Bruker vector22 FTIR (Bruker, Zurich, Switzerland). These solid samples were mixed with $\mathrm{KBr}$ and pressed to a disk for measurement. A Bruker ARX-300 NMR was used to record the ${ }^{1} \mathrm{H}-\mathrm{NMR}$ spectra of the GA, DSPE-PEG $2000-\mathrm{NH}_{2}$ and DSPE-PEG $2000-\mathrm{GA}$ samples. $\mathrm{CDCl}_{3}$ was used as test solvent.

\subsection{Measurement of Particles Size and Zeta Potential}

Particle size and zeta potential of NLCs were assayed by a Zetasizer Nano 2S-90 (Malvern Instruments, Worcestershire, UK).

\subsection{Transmission Electron Microscopy (TEM)}

The morphology of NLCs were observed using TEM (JEM-1200EX, JEOL Co., Tokyo, Japan). An amount of NLCs was diluted to a suitable concentration with distilled water, placed on a copper grid and stained with $2 \%$ phosphotungstic acid solution. After drying at room temperature, the grid was examined by TEM.

\subsection{Drug Encapsulation}

The encapsulation efficiency of curcumin in the nanostructured lipid carriers (NLCs) was determined using the Sephadex G-50 mini-column centrifugation method [29]. The drug content was detected by a UV method.

\subsection{In Vitro Cellular Uptake and In Vitro Cytotoxicity}

The $\mathrm{HepG}_{2}$ cell line was used to investigate cellular uptake of Cur-solution, Cur-NLC, Cur-PEG-NLC. Additionally, the effect of drug-loaded nanocarriers with different ligands on the cellular uptake was also evaluated. After routine culture of $0.5,1,2,4$ or $6 \mathrm{~h}$, the cellular uptake was analyzed by fluorescence spectrophotometry $\left(\lambda_{\mathrm{ex}}=471 \mathrm{~nm}, \lambda_{\mathrm{em}}=541 \mathrm{~nm}\right)$. All samples were analysed three times.

The $\mathrm{HepG}_{2}$ cells were cultured in DMED medium supplemented with $10 \% \mathrm{FBS}$ at $37{ }^{\circ} \mathrm{C}$ with $5 \%$ $\mathrm{CO}_{2}$ under fully humidified conditions. Cells were seeded onto a 96-well culture plate in $200 \mu \mathrm{L}$ of culture medium. After incubation for $24 \mathrm{~h}$, Cur-solution, Cur-NLC, Cur-PEG-NLC and Cur-GA10\%PEG-NLC at various concentrations were added into each well. The cells were cultured for additional 24, 48 or $72 \mathrm{~h}$, followed by addition of $20 \mu \mathrm{L}$ MTT solution $(5 \mu \mathrm{g} / \mathrm{mL})$ to each well for further incubation of $4 \mathrm{~h}$. The supernatant was removed carefully. Then $150 \mu \mathrm{L}$ of DMSO was added to each well and vibrated for 10 min until the formazan crystals were completely dissolved. The absorbance was measured by a TECAN SPECTRA instrument (TECAN Co., Männedorf, Switzerland).

$\mathrm{IC}_{50}$ software (RM6240) was used to calculate the $\mathrm{IC}_{50}$ values (concentration that inhibits cellular activity by $50 \%$ compared to that of the control group) of the free drug and the different curcuminloaded nanocarrier formulations at 24,48 or $72 \mathrm{~h}$. 


\section{Conclusions}

This research studied the preparation and the particle characterization of Cur-NLC, Cur-PEG-NLC and Cur-GA-PEG-NLC, and also studied their in vitro cellular uptake and in vitro cytotoxicity. CurGA-PEG-NLC has been successfully prepared by the film ultrasound method. Cur-GA-PEG-NLC displayed a spherical appearance, an optimal particle size and a high entrapment efficiency. The results of in vitro $\mathrm{HepG}_{2}$ cellular uptake showed that the GA-mediated nanostructured lipid carrier has the highest cellular uptake. Cellular uptake tendency at $6 \mathrm{~h}$ showed following order: Cur-GA10\%-PEGNLC $>$ Cur-NLC $>$ Cur-PEG-NLC $>$ Cur-solution. Cur-GA-PEG-NLC also demonstrated an increased in vitro cytotoxicity compared to that of free drug solution against the $\mathrm{HepG}_{2}$ cell line. Pharmacokinetic and in vivo efficacy studies of Cur-GA-PEG-NLC will be conducted in future work.

\section{Acknowledgments}

This work was supported by grants from Science and Technology Program of Shenyang (F11-144-9-00).

\section{Author Contributions}

Conceived and designed the experiments: Yang Chu, Ming-Yan Jiang. Performed the experiment: Dan Li, Yang Chu and Xiao-Jin He. Analyzed the data: Yang Chu, Dan Li and Yi-Fan Luo. Wrote the paper: Yang Chu and Yi-Fan Luo. Reviewed and edited the manuscript: Yang Chu, Yi-Fan Luo, and Ming-Yan Jiang. All authors read and approved the manuscript.

\section{Conflicts of Interest}

The authors declare no conflict of interest.

\section{References}

1. Yallapu, M.M.; Jaqqi, M.; Chauhan, S.C. Curcumin nanoformulationd: A future nanomedicine for cancer. Drug Discov. Today 2012, 17, 71-80.

2. Huang, M.T.; Newmark, H.L.; Frenkel, K. Inhibitory effects of curcumin on tumorigenesis in mice. J. Cell. Biochem. Suppl. 1997, 27, 26-34.

3. Siddiqui, A.M.; Cui, X.; Wu, R.; Dong, W.; Zhou, M.; Hu, M.; Simms, H.H.; Wang, P. The antiinflammatory effect of curcumin in an experimental model of sepsis is mediated by up-regulation of peroxisome proliferatoractivated receptor-gamma. Crit. Care Med. 2006, 34, 1874-1882.

4. Kumar, K.; Rai. A.K. Proniosomal formulation of curcumin having anti-inflammatory and anti-arthritic activity in different experimental animal models. Pharmazie 2012, 67, 852-857.

5. Menon, V.P.; Sudheer A.R. Antioxidant and anti-inflammatory properties of curcumin. Adv. Exp. Med. Biol. 2007, 595, 105-125.

6. Paek, E.J.; Jeon, C.H.; Ko, G.; Kim, J.; Sohn, D.H. Protective effect of curcumin in rat liver injury induced by carbon tetrachloride. J. Pharm. Pharmacol. 2000, 52, 437-440. 
7. Ireson, C.R.; Jones, D.J.; Orr, S.; Coughtrie, M.W.; Boocock, D.J.; Williams, M.L.; Farmer, P.B.; Steward, W.P.; Gescher, A.J. Metabolism of the cancer chemopreventive agent curcumin in human and rat intestine. Cancer Epidemiol. Biomarkers Prev. 2002, 11, 105-111.

8. Maheshwari, R.K.; Singh, A.K.; Gaddipati. J.; Srimal, R.C. Multiple biological activities of curcumin: A short review. Life Sci. 2006, 78, 2081-2087.

9. Yang, C.L.; Liu, Y.Y.; Ma, Y.G.; Xue, Y.X.; Liu, D.G.; Ren, Y.; Liu, X.B.; Li, Y.; Li, Z. Curcumin blocks small cell lung cancer cells migration, invasion, angiogenesis, cell cycle and neoplasia through Janus kinase-STAT3 signalling pathway. PLoS One 2012, 7, e37960.

10. Huang, M.T.; Smart, R.C.; Wong, C.Q.; Conney, A.H. Inhibitory effect of curcumin, chlorogenic acid, caffeic acid and ferulic acid on tumor promotion in mouse skin by 12-Otetradecanoylphorbol-13-acetate. Cancer Res. 1988, 48, 5941-5946.

11. Pereira, M.A.; Grubbs, C.J.; Barnes, L.H.; Li, H.; Olson, G.R.; Eto, I.; Juliana, M.; Whitaker, L.M.; Kelloff, G.J.; Steele, V.E.; et al. Effects of the phytochemicals, curcumin and quercetin, upon azoxymethane-induced colon cancer and 7,12-dimethylbenz[a]anthracene-induced mammary cancer in rats. Carcinogenesis 1996, 17, 1305-1311.

12. Huang, M.T.; Loum Y.R.; Mam W.; Newmark, H.L.; Reuhl, K.R.; Conney, A.H. Inhibitory effects of dietary curcumin on forestomach, duodenal, and colon carcinogenesis in mice. Cancer Res. 1994, 54, 5841-5847.

13. Rao, C.V.; Rivenson, A.; Simi, B.; Reddy, B.S. Chemoprevention of colon carcinogenesis by dietary curcumin, a naturally occurring plant phenolic compound. Cancer Res. 1995, 55, 259-266.

14. Zhang, F.; Altorki, N.K.; Mestre, J.R.; Subbaramaiah, K.; Dannenberg, A.J. Curcumin inhibits cyclooxygenase-2 transcription in bile acid- and phorbol ester-treated human gastrointestinal epithelial cells. Carcinogenesis 1999, 20, 445-451.

15. Wang, W.; Zhang, B.; Chen, H.; Zhang, L. Anticancer activities of curcum in on human hepatocarcinoma cell line Sk-hep-1. Zhongguo Zhong Yao Za Zhi 2010, 35, 485-488.

16. Churchill, M.; Chadburn, A.; Bilinski, R.T.; Bertagnolli, M.M. Inhibition of intestinal tumors by curcumin associated with changes in the intestinal immune cell profile. J. Surg. Res. 2000, 89, 169-175.

17. Muller, R.H.; Radtke. M.; Wissing, S.A. Nanostructured lipid matrices for improved microencapsulation of drugs. Int. J. Pharm. 2002, 242, 121-128.

18. Jenning, V.; Thunemann, A.F.; Gohla, S.H. Characterisation of a novel solid lipid nanoparticle carrier system based on binary mixtures of liquid and solid lipids. Int. J. Pharm. 2000, 199, 167-177.

19. Jenning, V.; Mader, K.; Gohla, S. Solid lipid nanoparticles (SLN) based on binary mixtures of liquid and solid lipids: A 1H-NMR study. Int. J. Pharm. 2000, 205, 15-21.

20. Mehnert, W.; Mader, K. Solid lipid nanoparticles: Production, characterization and applications. Adv. Drug. Deliv. Rev. 2001, 47, 165-196.

21. Muller, R.H.; Mader, K.; Gohla, S. Solid lipid nanoparticles (SLN) for controlled drug delivery-a review of the state of the art. Eur. J. Pharm. Biopharm. 2000, 50, 161-177.

22. Muller, R.H.; Gohla, S.; Dingler, A.; Schneppe, T. Large Scale Production of Solid Lipid Nanoparticles (SLNTM) and Nanosuspensions (DissoCubesTM). In Handbook of Pharmaceutical 
Controlled Release Technology; Wise, D.L., Ed.; Marcel Dekker Inc: New York, NY, USA, 2000; pp. 359-376.

23. Uner, M. Preparation, characterization and physico-chemical properties of solid lipid nanoparticles (SLN) and nanostructured lipid carriers (NLC): Their benefits as colloidal drug carrier systems. Pharmazie 2006, 61, 375-386.

24. Mao, S.J.; Hou, S.X.; He, R.; Zhang, L.K.; Wei, D.P.; Bi, Y.Q.; Jin, H. Uptake of albumin nanoparticle surface modified with glycyrrhizin by primary cultured rat hepatocytes. World $J$. Gastroenterol. 2005, 11, 3075-3079.

25. Lin, A.; Liu, Y.; Huang, Y.; Sun, J.; Wu, Z.; Zhang, X.; Ping, Q. Glycyrrhizin surface-modified chitosan nanoparticles for hepatocyte-targeted delivery. Int. J. Pharm. 2008, 359, 247-253.

26. Mao, S.J.; Bi, Y.Q.; Jin, H.; Wei, D.P.; He, R.; Hou, S.X. Preparation, characterization and uptake by primary cultured rat hepatocytes of liposomes surface-modified withglycyrrhetinic acid. Pharmazie 2007, 62, 614-619.

27. Kato, K.; Uchida, E.; Kang, E.T.; Uyama, Y.; Ikada, Y. Polymer surface with graft chains. Prog. Polym. Sci. 2003, 28, 209-259.

28. Nam, H.Y.; Kwon, S.M.; Chung, H.; Lee, S.Y.; Kwon, S.H.; Jeon, H.; Kim, Y.; Park, J.H.; Kim, J.; Her, S.; et al. Cellular uptake mechanism and intracellular fate of hydrophobically modified glycol chitosan nanoparticles. J. Control. Release 2009, 135, 259-267.

29. Zhou, L.L.; Wang, Y.; Liu, Q.F. Study on determination of entrapment efficiency of sinomenine liposomes. Zhongguo Zhong Yao Za Zhi 2006, 31, 731-734.

Sample Availability: Samples of Cur-NLC, Cur-PEG-NLC and Cur-GA-PEG-NLC are available from the authors.

(C) 2014 by the authors; licensee MDPI, Basel, Switzerland. This article is an open access article distributed under the terms and conditions of the Creative Commons Attribution license (http://creativecommons.org/licenses/by/3.0/). 